Jul 11th, 10:30 AM - 10:50 AM

\title{
Theoretical foundations of human decision-making in agent-based land use models - a review
}

Jule Schulze

Helmholtz Centre for Environmental Research, jule.schulze@ufz.de

Birgit Müller

Helmholtz Centre for Environmental Research, birgit.mueller@ufz.de

Carsten M. Buchmann

Helmholtz Centre for Environmental Research, University of Hohenheim, carsten.buchmann@ufz.de

Gunner Dressler

Helmholtz Centre for Environmental Research, gunnar.dressler@ufz.de

Niklas Hase

Helmholtz Centre for Environmental Research, niklas.hase@ufz.de

See next page for additional authors

Follow this and additional works at: https://scholarsarchive.byu.edu/iemssconference

Part of the Civil Engineering Commons, Data Storage Systems Commons, Environmental Engineering Commons, Hydraulic Engineering Commons, and the Other Civil and Environmental Engineering Commons

Schulze, Jule; Müller, Birgit; Buchmann, Carsten M.; Dressler, Gunner; Hase, Niklas; Hoffmann, Falk; John, Felix; Guo, Cheng; Klassert, Christian; Lauf, Thomas; Liebelt, Veronika; Nolzen, Henning; Pannicke, Nadine; Wise, Hanna; Schwarz, Nina; and Groeneveld, Jürgen, "Theoretical foundations of human decision-making in agent-based land use models - a review" (2016). International Congress on Environmental Modelling and Software. 4.

https://scholarsarchive.byu.edu/iemssconference/2016/Stream-D/4 


\section{Presenter/Author Information}

Jule Schulze, Birgit Müller, Carsten M. Buchmann, Gunner Dressler, Niklas Hase, Falk Hoffmann, Felix John, Cheng Guo, Christian Klassert, Thomas Lauf, Veronika Liebelt, Henning Nolzen, Nadine Pannicke, Hanna Wise, Nina Schwarz, and Jürgen Groeneveld 


\title{
Theoretical foundations of human decision-making in agent-based land use models - a review
}

\author{
Jule Schulze $^{a}$, Birgit Müller ${ }^{a}$, Carsten M. Buchmann ${ }^{b, c}$, Gunnar Dressler ${ }^{a}$, Niklas Hase ${ }^{a}$, Falk \\ Hoffmann $^{a, b}$, Felix John ${ }^{a}$, Cheng Guo ${ }^{b}$, Christian Klassert ${ }^{d, e}$, Thomas Lauf ${ }^{d}$, Veronika Liebelt ${ }^{b}$, \\ Henning Nolzen ${ }^{\mathrm{a}}$, Nadine Pannicke ${ }^{\mathrm{d}}$, Hanna Weise ${ }^{\dagger}$, Nina Schwarz $^{\mathrm{b}}$, Jürgen Groeneveld ${ }^{\mathrm{a}}$ \\ ${ }^{a}$ Department of Ecological Modelling, Helmholtz Centre for Environmental Research - UFZ, \\ Permoserstr.15,04318 Leipzig, Germany (jule.schulze@ufz.de, birgit.mueller@ufz.de, \\ gunnar.dressler@ufz.de,niklas.hase@ufz.de,falk.hoffmann@ufz.de,felix.john@ufz.de, \\ henning.nolzen@ufz.de,juergen.groeneveld@ufz.de) \\ ${ }^{b}$ Department of Computational Landscape Ecology, Helmholtz Centre for Environmental Research - \\ UFZ, Permoserstr.15, 04318 Leipzig, Germany (carsten.buchmann@ufz.de, cheng.guo@ufz.de, \\ veronika.liebelt@ufz.de,nina.schwarz@ufz.de) \\ 'University of Hohenheim, Institute of Landscape and Plant Ecology, 70593 Stuttgart, Germany \\ ${ }^{d}$ Department of Economics, Helmholtz Centre for Environmental Research - UFZ, Permoserstr. 15, \\ 04318 Leipzig, Germany (christian.klassert@ufz.de, thomas.lauf@ufz.de, nadine.pannicke@ufz.de) \\ ${ }^{e}$ Leipzig University, Institute of Infrastructure and Resources Management, Faculty of \\ Economics, Grimmaische Str. 12, 04109 Leipzig, Germany \\ ${ }^{f}$ Freie Universität Berlin, Institute of Biology, Biodiversity and Ecological Modeling, \\ Altensteinstr. 6, D-14195 Berlin, Germany (hanna.weise@fu-berlin.de)
}

\begin{abstract}
Recent reviews stated that the complex and context-dependent nature of human decisionmaking resulted in ad-hoc representations of human decision in agent-based land use change models (LUCC ABMs) and that these representations are often not explicitly grounded in theory. However, a systematic survey on the characteristics (e.g. uncertainty, adaptation, learning, interactions and heterogeneities of agents) of the representation of human decision in LUCC ABMs is missing. To inform this debate we performed a quantitative review of 134 LUCC ABM papers using a standardised questionnaire with a particular focus on the characteristics and the theoretical foundation of human decision-making. Thereby, we investigated whether implementations of human decision-making in current LUCC ABMs are theory based. Additionally, we assessed to which degree key factors such as learning, interaction or economic, environmental or social influence factors are considered in human decision making sub-models. We show that most human decision sub-models are not explicitly based on a specific theory and if so they are mostly based on economic theories. In contrast, promising psychological theories such as the theory of planned behaviour are the exception. The key factors of human decision sub-models showed a huge diversity and are not strongly related to neither the characteristics of the specific studied systems (e.g. rural vs. urban or its geographic location) nor the applied theoretical paradigm. We finish by presenting approaches for consolidating and enlarging the theoretical basis for modelling human decision-making.
\end{abstract}

Keywords: adaptation; heterogeneity; human behaviour; learning; multi-agent systems; ODD+D 